\title{
PENGARUH BERBAGAI KONSENTRASI DAN METODE APLIKASI HORMON GA TERHADAP PERTUMBUHAN DAN HASIL TANAMAN BROKOLI KULTIVAR LUCKY DI LEMBANG
}

\author{
DENINTA N, T.M. ONGGO, KUSUMIYATI \\ Jurusan Agroteknologi, Universitas Padjadjaran, Jatinangor \\ E-mail korespondensi : nedya13deninta@gmail.com
}

\begin{abstract}
Broccoli's yield from side shoots was expected to increase with $\mathrm{GA}_{3}$ application, due to the translocation of nutrients faster and better towards the side shoots. The experiment was carried out to study the interaction between concentration and application method of $\mathrm{GA}_{3}$ on growth and yield of broccoli. The experiment was conducted from Februari until Mei 2016 at CV. Agro Duta Farm, located in Cisarua - West Bandung, at an elevation of $1.100 \mathrm{~m}$ above the sea level. The experimental design used was Factorial Randomized Block Design (FRBD) with three replications, consisted of two factors and three levels. The first factor was concentration of $\mathrm{GA}_{3}$, comprised of $25 \mathrm{mg} / \mathrm{L}, 50 \mathrm{mg} / \mathrm{L}$, and $100 \mathrm{mg} / \mathrm{L}$. The second factor was application method of $\mathrm{GA}_{3}$, comprised of three levels : seedling soaking for 24 hours, foliar spray at 15 and 25 DAT, seedling soaking for 24 hours and foliar spray at 15 DAT. The results showed that there were not interaction between concentration and application method of $\mathrm{GA}_{3}$ on growth and yield component. $\mathrm{GA} 3100 \mathrm{mg} / \mathrm{L}$ significantly increased the percentage of weight and amount B's quality, and decreased the percentage of weight and amount C's quality from side shoots of broccoli. The higher percentage of weight and amount B's quality from side shoots were obtained from seedling soaking of $\mathrm{GA}_{3}$ for 24 hours.
\end{abstract}

Keywords: $\mathrm{GA}_{3}$, Concentration, Application Method, Growth and Yield, Broccoli

\section{PENDAHULUAN}

Tanaman brokoli termasuk dalam famili kubiskubisan atau Brassicaceae yang merupakan salah satu tanaman yang bakal bunganya dimanfaatkan sebagai sayuran. Brokoli juga kaya akan gizi dan mengandung berbagai vitamin yang bermanfaat bagi kesehatan tubuh manusia. Brokoli kultivar Lucky merupakan kultivar yang banyak ditanam di Jawa Barat, keunggulan kultivar tersebut yaitu mempunyai produktivitas yang tinggi, kualitas hasil yang baik, dan lebih renyah dibandingkan jenis brokoli lain.

Permintaan pasar modern terhadap brokoli mengalami peningkatan dari tahun ke tahun. Menurut data United States Agency International Development (USAID 2013) chapter Indonesia, permintaan terhadap brokoli di Indonesia mengalami peningkatan 15-20\% per tahun. Tingginya permintaan tersebut tidak diimbangi dengan kuantitas, kualitas, dan kontinuitas produksi yang memadai dan produksi yang masih rendah, hal ini menyebabkan tingginya import brokoli dari beberapa negara (Yanto $d k k ., 2015$ ).

Brokoli kultivar Lucky berpotensi menghasilkan massa bunga dengan ukuran yang bisa mencapai $700 \mathrm{~g}$, namun ukuran yang terlalu besar tidak disukai oleh konsumen. Hasil dan kualitas yang baik didapatkan dengan memanen brokoli sebelum ukuran bunga mencapai maksimum, yaitu bila telah memasuki kriteria kualitas A (300-350 g). Setelah massa bunga utama dipotong, maka massa bunga berikutnya akan tumbuh dari tunas samping (sirung) dan memiliki potensi untuk dipasarkan. Permasalahan di lapangan, tunas samping memiliki jumlah yang tidak seragam dan ukuran massa bunga dari tunas samping kecil. Pengaturan jumlah tunas samping dan teknik budidaya yang mampu merangsang aliran fotosintat ke tunas samping diperlukan untuk menghasilkan massa bunga dari tunas samping yang baik.

Teknik budidaya yang dapat meningkatkan kualitas dan merangsang pembentukan massa bunga utama serta massa bunga dari tunas samping diperlukan untuk peningkatan hasil tanaman brokoli, salah satu alternatif yang dapat dilakukan yaitu pemberian zat pengatur tumbuh sintetik dengan berbagai konsentrasi. Pemberian zat pengatur tumbuh/hormon sintetik $\mathrm{GA}_{3}$ dapat dilakukan untuk meningkatkan pertumbuhan dan perkembangan brokoli, baik dari massa bunga utama maupun dari tunas samping.

Menurut Widyastuti dan Tjokrokusumo (2007), GA merupakan hormon giberelin sintetik yang berfungsi untuk pemanjangan sel, merangsang pertumbuhan, mengendalikan pertumbuhan seperti pembungaan, dan terlibat dalam proses regulasi perkembangan tanaman seperti halnya auksin.

Penelitian Singh et al., (2011) menunjukkan bahwa perlakuan $\mathrm{GA}_{3}$ dan kinetin dengan konsentrasi $30 \mathrm{mg} / \mathrm{L}$ + $30 \mathrm{mg} / \mathrm{L}$ melalui aplikasi perendaman bibit selama 24 jam pada tanaman brokoli mampu memberikan pengaruh lebih tinggi terhadap bobot tanaman, jumlah daun, inisiasi pembungaan, dan waktu panen yang lebih cepat dibandingkan perlakuan kontrol. Menurut Patel et al., (2011), pemberian $\mathrm{GA}_{3}$ pada tanaman kubis bunga dengan konsentrasi $50 \mathrm{mg} / \mathrm{L}$ melalui aplikasi penyemprotan daun memberikan hasil lebih baik pada diameter curd dan hasil curd dibandingkan dengan konsentrasi $\mathrm{GA}_{3} 75 \mathrm{mg} / \mathrm{L}$ dan $100 \mathrm{mg} / \mathrm{L}$ serta aplikasi melalui perendaman bibit. Alasan yang mendukung hal terse- 
but yaitu asam giberelat merangsang pertumbu-han vegetatif dan melibatkan inisiasi pembelahan sel.

\section{METODE}

Penelitian dilakukan di lahan CV. Agro Duta Farm, Kecamatan Cisarua, Kabupaten Bandung Barat, Jawa Barat dengan ketinggian tempat 1.100 mdpl. Penelitian dilaksanakan mulai dari bulan Februari hingga Mei 2016.

Rancangan percobaan yang digunakan adalah Rancangan Acak Kelompok (RAK) pola faktorial dengan dua faktor dan tiga ulangan. Faktor pertama adalah konsentrasi $\mathrm{GA}_{3}(\mathrm{~K})$ terdiri dari tiga taraf, yaitu $\mathrm{k}_{1}$ (25 $\mathrm{mg} / \mathrm{L}), \mathrm{k}_{2}(50 \mathrm{mg} / \mathrm{L})$, dan $\mathrm{k}_{3}(100 \mathrm{mg} / \mathrm{L})$. Faktor kedua adalah metode aplikasi $\mathrm{GA}_{3}(\mathrm{M})$ terdiri dari tiga taraf, yaitu $m_{1}$ (perendaman bibit selama 24 jam), $m_{2}$ (penyemprotan pada daun tanaman umur 15 dan 25 HST), dan $m_{3}$ (perendaman bibit selama 24 jam dan penyemprotan daun umur $15 \mathrm{HST}$ ). Setiap plot terdiri dari 10 tanaman. Jumlah sampel tiap plot 3 tanaman untuk pengamatan pertumbuhan dan data hasil diambil dari keseluruhan tanaman dalam plot.

Bahan-bahan yang digunakan dalam percobaan ini terdiri dari bibit brokoli kultivar Lucky, hormon sintetik $\mathrm{GA}_{3}$ Top Gib, media semai berupa arang sekam dan cocopeat, pupuk NPK Mutiara 16:16:16, pupuk NPK Mutiara 25:7:7, pupuk Ponska, pestisida dengan bahan aktif Klorantraniliprol $50 \mathrm{~g} / \mathrm{L}$ dan Profenofos $500 \mathrm{~g} / \mathrm{L}$. Brokoli ditanam di tanah yang telah dicampur dengan pupuk kotoran ayam. Pengamatan hasil pada penelitian ini dilakukan hingga kedua tunas samping menghasilkan massa bunga.

Pengamatan pertumbuhan meliputi: tinggi tanaman (cm), jumlah daun (helai), dan panjang daun $(\mathrm{cm})$. Pengamatan hasil dan kualitas meliputi: bobot kotor brokoli (kg/plot) dari massa bunga utama dan tunas samping, persentase bobot dan jumlah brokoli dari massa bunga utama dan tunas samping yang layak pasar dan tidak layak pasar, dan persentase bobot dan jumlah brokoli berdasarkan kualitas A, B, dan C. Pengaruh perlakuan diuji dengan uji $\mathrm{F}$ dengan taraf nyata $5 \%$, sedangkan untuk menguji perbedaan nilai rata-rata perlakuan dilakukan dengan uji Duncan pada taraf nyata $5 \%$.

\section{HASIL DAN PEMBAHASAN}

Pengamatan Pertumbuhan Tanaman. Data hasil analisis statistik menunjukkan bahwa tidak terjadi interaksi antara perlakuan konsentrasi $\mathrm{GA}_{3}$ dan metode aplikasi $\mathrm{GA}_{3}$ pada semua komponen pertumbuhan. Masing-masing faktor berpengaruh secara mandiri untuk panjang daun tanaman, akan tetapi kedua perlakuan tersebut tidak memberikan pengaruh untuk tinggi dan jumlah daun tanaman.

Berdasarkan data pada Tabel 1, konsentrasi GA 25 $\mathrm{mg} / \mathrm{L}$ dan $100 \mathrm{mg} / \mathrm{L}$ dapat meningkatkan panjang daun umur 4 MST, akan tetapi konsentrasi tersebut tidak memberikan pengaruh pada minggu ke 2, 3, dan 5 MST. Tabel 1 juga menunjukkan bahwa perlakuan metode aplikasi penyemprotan pada daun tanaman umur 15 dan 25 HST $\left(m_{2}\right)$ meningkatkan panjang daun pada 3 MST dibandingkan dengan kedua perlakuan lainnya.

Perkembangan daun sangat penting pada produksi tanaman budidaya agar dapat memaksimal-kan penyerapan cahaya dan asimilasi.Giberelin ber-fungsi dalam meningkatkan pembelahan sel sehingga dapat memperbesar ukuran daun. Menurut Aloni et al., (1986), GA A $_{3}$ mampu menstimulasi proses fotosintesis, meningkatakan laju transfer sukrosa dengan mekanisme gradien tekanan hidrostatik, mengatur laju transfer sukrosa pada floem dengan mekanisme loading dan unloading, bekerjasama dengan pengaturan turgor sel dan partisi fotosintat, mengatur asimilasi partisi sukrosa, sehingga mampu meningkatkan laju tumbuh relatif tanaman.

$\mathrm{GA}_{3}$ memiliki peran untuk mentranslokasikan nutrisi yang lebih cepat dan lebih baik dari akar ke bagian tanaman lain melalui floem. $\mathrm{GA}_{3}$ yang diberikan memberikan pengaruh terhadap pemanjangan sel, sehingga terjadi pemanjangan daun pada tahap vegetatif tanaman brokoli.Pemberian $\mathrm{GA}_{3}$ melalui metode aplikasi penyemprotan pada daun akan mempercepat penyerapan zat yang diberikan pada tanaman (Sumarni $d k k$., 2013).

\section{Pengamatan Hasil dan Kualitas Hasil.}

Tabel 2 menunjukkan bahwa konsentrasi dan metode aplikasi tidak memberikan pengaruh terhadap bobot kotor massa bunga utama, hal ini berbeda dengan bobot kotor yang dihasilkan massa bunga dari tunas samping. Konsentrasi $\mathrm{GA}_{3} 100 \mathrm{mg} / \mathrm{L}\left(\mathrm{k}_{3}\right)$ dan metode aplikasi perendaman bibit selama 24 jam $\left(\mathrm{m}_{1}\right)$ dapat meningkatkan bobot kotor massa bunga dari tunas samping dibandingkan dengan kedua perlakuan lainnya.

$\mathrm{GA}_{3}$ mampu meningkatkan pertambahan ukuran sel sehingga dapat menambah ukuran jaringan, ukuran organ, atau bagian-bagian tanaman secara keseluruhan, maupun bobot tanaman tersebut. Peningkatan pembelahan sel menghasilkan jumlah sel yang lebih banyak. Jumlah sel yang yang lebih banyak memungkinkan terjadinya peningkatan fotosintesis penghasil karbohidrat sehingga dapat mempengaruhi bobot tanaman (Brenner and Cheikh, 1995).

$\mathrm{GA}_{3}$ merupakan salah satu hormon yang bermanfaat dalam perombakan karbohidrat menjadi senyawasenyawa yang lebih sederhana seperti sukrosa dengan cara mengaktifkan enzim sukrosa-phospate-syntase (SPS). Enzim ini berperan dalam pembentukan sukrosa dari triose-P yang dapat diangkut ke bagian tanaman lain, salah satunya menuju organ generatif seperti massa bunga (Sarkar et al., 2014). 
Tabel 1.

Pengaruh Konsentrasi dan Metode Aplikasi $\mathrm{GA}_{3}$ terhadap Panjang Daun Brokoli Kultivar Lucky di Lembang pada 2-5 MST

\begin{tabular}{lrrrr}
\hline & Perlakuan & \multicolumn{4}{c}{ Rata-rata Panjang Daun (cm) } \\
\cline { 2 - 5 } & 2 MST & 3 MST & 4 MST & 5 MST \\
\hline Konsentrasi GA & (K) & & & \\
$\mathrm{k}_{1}=\mathrm{GA}_{3} 25 \mathrm{mg} / \mathrm{L}$ & 8,83 & 13,45 & $21,70 \mathrm{~b}$ & 26,59 \\
$\mathrm{k}_{2}=\mathrm{GA}_{3} 50 \mathrm{mg} / \mathrm{L}$ & 8,48 & 12,56 & $20,80 \mathrm{a}$ & 25,88 \\
$\mathrm{k}_{3}=\mathrm{GA}_{3} 100 \mathrm{mg} / \mathrm{L}$ & 8,64 & 13,19 & $22,05 \mathrm{~b}$ & 24,20 \\
\hline Metode Aplikasi GA & & & & \\
$\mathrm{m}_{1}=$ Perendaman bibit 24 jam & 8,36 & $12,70 \mathrm{a}$ & 21,95 & 26,14 \\
$\mathrm{~m}_{2}=$ Penyemprotan daun 15 dan 25 HST & 9,15 & $13,91 \mathrm{~b}$ & 21,34 & 25,41 \\
$\mathrm{~m}_{3}=$ Perendaman bibit 24 jam dan penyemprotan 15 HST & 8,43 & $12,58 \mathrm{a}$ & 21,26 & 25,12 \\
\hline
\end{tabular}

Keterangan : Nilai rata-rata yang diikuti oleh huruf yang sama pada kolom yang sama, menunjukkan tidak berbeda nyata berdasarkan uji Jarak Berganda Duncan $5 \%$

Tabel 2.

Pengaruh Konsentrasi dan Metode Aplikasi GA A $_{3}$ terhadap Bobot Kotor Brokoli dari Massa Bunga Utama dan Massa Bunga dari Tunas Samping

\begin{tabular}{|c|c|c|}
\hline Perlakuan & $\begin{array}{l}\text { Bobot Kotor Massa } \\
\text { bunga utama } \\
\text { (kg/plot) }\end{array}$ & $\begin{array}{l}\text { Bobot Kotor Massa bunga dari } \\
\text { tunas samping (kg/plot) }\end{array}$ \\
\hline \multicolumn{3}{|l|}{ Konsentrasi GA $\mathbf{A}_{3}(\mathrm{~K})$} \\
\hline $\mathrm{k}_{1}=\mathrm{GA}_{3} 25 \mathrm{mg} / \mathrm{L}$ & 3,86 & $3,73 \mathrm{a}$ \\
\hline $\mathrm{k}_{2}=\mathrm{GA}_{3} 50 \mathrm{mg} / \mathrm{L}$ & 3,67 & $3,64 \mathrm{a}$ \\
\hline $\mathrm{k}_{3}=\mathrm{GA}_{3} 100 \mathrm{mg} / \mathrm{L}$ & 4,32 & $4,05 b$ \\
\hline \multicolumn{3}{|l|}{ Metode Aplikasi GA $(\mathrm{M})$} \\
\hline $\mathrm{m}_{1}=$ Perendaman bibit 24 jam & 4,50 & $4,13 \mathrm{~b}$ \\
\hline $\mathrm{m}_{2}=$ Penyemprotan daun 15 dan $25 \mathrm{HST}$ & 3,62 & $3,63 \mathrm{a}$ \\
\hline $\begin{aligned} \mathrm{m}_{3}= & \text { Perendaman bibit } 24 \text { jam dan } \\
& \text { penyemprotan daun umur } 15 \mathrm{HST}\end{aligned}$ & 3,73 & 3,65 a \\
\hline
\end{tabular}

Keterangan : Nilai rata-rata yang diikuti oleh huruf yang sama pada kolom yang sama, menunjukkan tidak berbeda nyata berdasarkan uji Jarak Berganda Duncan $5 \%$

Tabel 3.

Pengaruh Konsentrasi dan Metode Aplikasi terhadap Persentase Bobot dan Jumlah Brokoli dari Massa Bunga Utama berdasarkan Kualitas A, B, dan C

\begin{tabular}{|c|c|c|c|c|c|c|}
\hline \multirow{3}{*}{ Perlakuan } & \multicolumn{6}{|c|}{ Persentase Bobot dan Jumlah Massa Bunga Utama } \\
\hline & \multicolumn{3}{|c|}{ Bobot (\%) } & \multicolumn{3}{|c|}{ Jumlah (\%) } \\
\hline & A & B & $\mathbf{C}$ & A & B & $\mathbf{C}$ \\
\hline \multicolumn{7}{|l|}{ Konsentrasi $\mathbf{G A}_{3}$} \\
\hline $\mathrm{k}_{1}=\mathrm{GA}_{3} 25 \mathrm{mg} / \mathrm{L}$ & $62,99 \mathrm{a}$ & 20,00 & $17,01 \mathrm{~b}$ & 39,75 & 31,19 & 29,07 \\
\hline $\mathrm{k}_{2}=\mathrm{GA}_{3} 50 \mathrm{mg} / \mathrm{L}$ & $76,00 \mathrm{~b}$ & 17,73 & 6,27 a & 47,74 & 33,13 & 19,13 \\
\hline $\mathrm{k}_{3}=\mathrm{GA}_{3} 100 \mathrm{mg} / \mathrm{L}$ & $79,16 \mathrm{~b}$ & 13,31 & 7,53 a & 54,38 & 26,64 & 18,98 \\
\hline \multicolumn{7}{|l|}{ Metode Aplikasi GA 3} \\
\hline $\mathrm{m}_{1}=$ Perendaman bibit 24 jam & 73,49 & 17,71 & 8,80 & 46,36 & 32,67 & 20,97 \\
\hline Penyemprotan daun 15 dan 25 HST & 74,55 & 15,48 & 9,97 & 50,94 & 24,44 & 24,62 \\
\hline $\begin{array}{l}\text { Perendaman bibit } 24 \text { jam dan } \\
\text { penyemprotan } 15 \text { HST }\end{array}$ & 70,12 & 17,85 & 12,03 & 44,55 & 33,87 & 21,58 \\
\hline
\end{tabular}


Tabel 3 menunjukkan bahwa konsentrasi $\mathrm{GA}_{3}$ $50 \mathrm{mg} / \mathrm{L}\left(\mathrm{k}_{2}\right)$ dan $100 \mathrm{mg} / \mathrm{L}\left(\mathrm{k}_{3}\right)$ dapat meningkatkan persentase bobot kualitas $A$ dan menurunkan persentase bobot kualitas $C$ pada massa bunga utama. Perlakuan metode aplikasi $\mathrm{GA}_{3}$ tidak memberikan pengaruh terhadap persentase bobot dan jumlah brokoli dari massa bunga utama berdasarkan kelas kualitas.

Berdasarkan data pada Tabel 4, pemberian $\mathrm{GA}_{3}$ dengan konsentrasi $100 \mathrm{mg} / \mathrm{L} \quad\left(\mathrm{k}_{3}\right)$ dapat meningkatkan persentase bobot dan jumlah kualitas $B$, serta menurunkan persentase bobot dan jumlah kualitas $C$ dibandingkan dengan $\mathrm{GA}_{3} 50 \mathrm{mg} / \mathrm{L}\left(\mathrm{k}_{2}\right)$ untuk massa bunga dari tunas samping, namun bila dibandingkan dengan aplikasi $\mathrm{GA}_{3} 25 \mathrm{mg} / \mathrm{L}$, persentase bobot dan jumlah massa bunga dari tunas samping tersebut sama. Pemberian $\mathrm{GA}_{3}$ pada konsentrasi dengan range sempit dapat menyebabkan pengaruh yang dihasilkan menjadi tidak berbeda. $\mathrm{GA}_{3}$ memberikan respons yang berbeda apabila konsentrasi yang digunakan memiliki range yang cukup luas (Gardner et al., 1985). Metode aplikasi perendaman bibit selama 24 jam $\left(m_{1}\right)$ menghasilkan persentase bobot dan jumlah kualitas B yang lebih tinggi dan kualitas $C$ yang lebih rendah dibandingkan dengan kedua perlakuan lainnya.

Pemberian $\mathrm{GA}_{3}$ melalui metode aplikasi penyemprotan pada daun tidak mempengaruhi persentase bobot dan jumlah massa bunga dari tunas samping berdasarkan kelas kualitas, hal ini bisa disebabkan karena pemberian hormon $\mathrm{GA}_{3}$ pada daun diberikan saat 15 dan $25 \mathrm{HST}$, sedangkan tunas samping muncul pertama kali sejak $10 \mathrm{HST}$. Penyemprotan $\mathrm{GA}_{3}$ melalui daun pada percobaan ini justru menurunkan persentase bobot dan jumlah kualitas $B$, seperti pada perlakuan perendaman bibit selama 24 jam dan penyemprotan pada daun umur $15 \mathrm{HST}\left(\mathrm{m}_{3}\right)$. Hal ini dapat terjadi karena metode aplikasi melalui daun lebih dipengaruhi oleh faktor lingkungan, sehingga pemberian $\mathrm{GA}_{3}$ pada tanaman dengan kondisi lingkungan yang tidak terkontrol dapat menyebabkan pemberian hormon menjadi tidak optimal serta menghambat kinerja penyerapan hormon yang diberikan ke tanaman (inhibitor). Metode aplikasi yang berperan terhadap kelas kualitas massa bunga dari tunas samping yaitu perendaman bibit selama 24 jam.

Gunawan et al., (1986) menyebutkan bahwa pemberian $\mathrm{GA}_{3}$ dengan konsentrasi yang sesuai dapat mempengaruhi proses biokimia dalam tanaman, sehingga proses fotosintesis meningkat dan fotosintatnya dapat digunakan untuk menentukan kebutuhan dalam proses pembentukan organ generatif hingga tanaman dapat dipanen. Pemberian giberelin mengakibatkan kegiatan metabolisme dan laju fotosintesis meningkat, sehingga mampu meningkatkan karbohidrat yang berperan untuk perkembangan tanaman.

Tabel 4.

Pengaruh Konsentrasi dan Metode Aplikasi terhadap Persentase Bobot dan Jumlah Brokoli pada Massa Bunga dari Tunas Samping berdasarkan Kualitas A, B, dan C

\begin{tabular}{|c|c|c|c|c|c|c|}
\hline \multirow[b]{3}{*}{ Perlakuan } & \multicolumn{6}{|c|}{ Persentase Bobot dan Jumlah Massa Bunga dari Tunas Samping } \\
\hline & \multicolumn{3}{|c|}{ Bobot (\%) } & \multicolumn{3}{|c|}{ Jumlah (\%) } \\
\hline & A & B & $\mathbf{C}$ & A & B & $\mathbf{C}$ \\
\hline \multicolumn{7}{|l|}{ Konsentrasi GA $\mathbf{G}_{3}(\mathrm{~K})$} \\
\hline $\mathrm{k}_{1}=\mathrm{GA}_{3} 25 \mathrm{mg} / \mathrm{L}$ & 1,08 & $22,88 \mathrm{ab}$ & $76,04 \mathrm{a}$ & 1,04 & $22,58 a b$ & 76,38 a \\
\hline $\mathrm{k}_{2}=\mathrm{GA}_{3} 50 \mathrm{mg} / \mathrm{L}$ & 0,00 & 10,85 a & 89,15 b & 0,00 & 10,74 a & $89,26 \mathrm{~b}$ \\
\hline $\mathrm{k}_{3}=\mathrm{GA}_{3} 100 \mathrm{mg} / \mathrm{L}$ & 3,23 & $29,59 \mathrm{~b}$ & 67,18 a & 3,20 & $29,42 b$ & 67,38 a \\
\hline \multicolumn{7}{|l|}{ Metode Aplikasi GA $(\mathrm{M})$} \\
\hline $\begin{array}{l}\mathrm{m}_{1}=\text { Perendaman bibit } 24 \text { jam } \\
\mathrm{m}_{2}=\text { Penyemprotan daun } 15\end{array}$ & 3,73 & $36,19 \mathrm{~b}$ & $60,08 \mathrm{a}$ & 3,32 & 35,96 b & 60,72 a \\
\hline dan 25 HST & 0,94 & 9,95 a & 89,11 b & 0,93 & 9,84 a & $89,23 \mathrm{~b}$ \\
\hline $\begin{aligned} \mathrm{m}_{3}= & \text { Perendaman bibit } 24 \text { jam } \\
& \text { dan penyemprotan daun } \\
& \text { umur } 15 \mathrm{HST}\end{aligned}$ & 0,00 & 17,18 a & $82,82 \mathrm{~b}$ & 0,00 & 16,93 a & $83,07 \mathrm{~b}$ \\
\hline
\end{tabular}

Keterangan : Nilai rata-rata yang diikuti oleh huruf yang sama pada kolom yang sama, menunjukkan tidak berbeda nyata berdasarkan uji Jarak Berganda Duncan $5 \%$ 


\section{SIMPULAN}

Tidak terlihat hubungan antara pengaruh konsentrasi dan metode aplikasi $\mathrm{GA}_{3}$ terhadap pertumbuhan dan hasil tanaman brokoli kultivar Lucky di Lembang.

Aplikasi $\mathrm{GA}_{3} 100 \mathrm{mg} / \mathrm{L}$ meningkatkan ukuran panjang daun tanaman dan bobot kotor massa bunga dari tunas samping. Aplikasi $\mathrm{GA}_{3} 50$ dan $100 \mathrm{mg} / \mathrm{L}$ meningkatkan persentase bobot kualitas $\mathrm{A}$ dan menurunkan persentase bobot kualitas $C$ dari massa bunga utama. Aplikasi $\mathrm{GA}_{3} 100 \mathrm{mg} / \mathrm{L}$ meningkatkan persentase bobot dan jumlah kualitas B pada tunas samping, serta menurunkan persentase bobot dan jumlah kualitas $C$.

Metode aplikasi perendaman bibit selama 24 jam meningkatkan bobot kotor serta meningkatkan persentase bobot dan jumlah kualitas $B$ dan menurunkan persentase bobot dan jumlah kualitas $\mathrm{C}$ massa bunga dari tunas samping.

\section{PUSTAKA}

Aloni, B., J. Daie, R.E. Wyse. 1986. Enchancement of ${ }^{14}$ C- sucrose Export from Source Leaves of Vibiafaba by $\mathrm{GA}_{3}$. In : Plant Hormones, Plant Physiology (82) : 962-966.

Brenner, M.L., and N. Cheikh. 1995. The Role of Hormones in Photosynthate Partitioning and Seed Filling. In:Plant Hormones, Physiology, Biochemistry and Molecular Biology (2) : 649670.

Gardner, F.P., R.B. Pearce, and R.L. Mitcheal. 1985. Phsyiology of Crop Plants. lowa State University Press, Ames : 164-186.
Naeem N., M. Ishtiaq, P. Khan, N. Mohammad, J. Khan, and B. Jamiher. 2001. Effect of Gibberellic Acid on Growth and Yield of Tomato Cv. Roma. Online Journal of Biological Sciences1 (6): 448-450.

Patel V.M., N.K. Patel, and S.R. Chaudhari.2011. Influence of $\mathrm{GA}_{3}$ and NAA on Yield Parameters of Cauliflower Cv. Snowball-16. International Journal of Forestry and International Forestry Crop Improvement 2(1) : 100-111.

Sarkar, M.D., M.S. Jahan, M.H. Kabir, and R.N. Rojono.2014. Yield and Quality of Broccoli Regulated by Plant Hormones. Department of Horticulture Sher-e-Bangla Agricultural University 1 (3) : 65-80.

Singh, Manjit, D.K. Rana, and J.M.S. Rawat.2011. Effect of $\mathrm{GA}_{3}$ and Kinetin on Growth, Yield, and Quality of Sprouting Broccoli (Brassica oleracea var. italica). Department of Horticulture, Chauras Campus, HNB Garhwal University 2 (2).

Sumarni, N., dan Sumiati. 2001. Pengaruh Vernalisasi, Giberelin, dan Auxin terhadap Pembungaan dan Hasil Biji Bawang Merah. Jurnal Balai Penelitian Tanaman Sayuran Bandung 11 (1) :1-8.

Widyastuti, N.I., dan Tjokrokusumo. 2007. Peranan Beberapa Zat Pengatur Tumbuh (ZPT) Tanaman pada Kultur In Vitro. Jurnal Sains dan Teknologi Indonesia 3 (5) : 55-63.

Yanto, D.M., T. Irmasnyah, dan E.T.S. Ferry. Respons Pertumbuhan dan Produksi Brokoli Terhadap Pemberian Pupuk Kandang Ayam dan Jamur Pelarut Fosfat. Jurnal Online Agroekoteknologi 3 (1) : 198-205 